\title{
A INFLUÊNCIA DAS SAFRAS NO MUNICÍPIO DE FRUTAL
}

\author{
FERREIRA, Patrik Eduardo da Silva ${ }^{52}$ \\ SANTOS, Geisiane Rodrigues dos $^{53}$ \\ Izabel Cristina Taceli ${ }^{54}$
}

\begin{abstract}
RESUMO: O presente artigo versa sobre o estudo do cultivo temporário que compreende os períodos entre 2004 a 2014, e objetivou mostrar a evolução da produção agrícola no município de Frutal, em Minas Gerais. A coleta foi originada de fontes de informação, disponibilizadas no site do Instituto Brasileiro de Geografia e Estatística - IBGE, sendo que para a compilação dos dados foi utilizado o software denominado por Excel. A ideia central partiu de um grupo de pesquisadores interdisciplinares das áreas de Geografia e Estatística que apontaram para resultados de crescimento significativos a partir do ano de 2000 , representando um valor de $28 \%$ de um total de $40 \%$ da população do município de Frutal - MG. Paralelamente, observa-se o crescimento posterior da plantação de cana-deaçúcar nos meados de 2004, assim com indícios de que com houve um aumento da população residente da cidade de Frutal. Portanto os resultados obtidos a partir do desdobramento de um projeto de pesquisa financiados pelo Programa Institucional de Iniciação Científica Júnior - BIC JR UEMG / CNPq / FAPEMIG, em vigência de março de 2015 a fevereiro de 2016, enfatizou-se o tratamento de Dados e a Modelagem Matemática. Tema este que tem sido estudado continuamente e com diversos desdobramentos devido ao impacto deste cultivo na cidade e região sudeste, norteando assim inúmeras pesquisas.
\end{abstract}

PALAVRAS CHAVE: Evolução da Cultura de cana de açúcar, Tratamento de Dados, Modelagem Matemática.

ABSTRACT: This article deals with cultivation temporary study comprising the periods between 2004 to 2014 and aimed to show the evolution of agricultural production in the municipality of Frutal in Minas Gerais. The collection originated from sources of information, made available on the website of the Brazilian Institute of geography and statistics - IBGE, and for the compilation of the data has been used software called by Excel. And the central idea came from a group of interdisciplinary researchers from the fields of geography and statistics that pointed to significant growth results from the year 2000, repres enting a value of $28 \%$ to a total of $40 \%$ of the population of the municipality of Frutal - MG. In parallel, the subsequent growth of planting sugarcane in mid-2004, as well as indications that with an increase of the resident population of the city of Frutal. Therefore the results obtained from the unfolding of a research project funded by the Institutional Programme Junior scientific initiation - BIC JR UEMG/CNPq/FAPEMIG in March 2015 period to February 2016, emphasizing on the treatment of Data and mathematical modeling. Which has been studied continuously and with various developments due to the impact of this cultivation in the city and the Southeast region, guided so many surveys.

KEYWORDS: Evolution of the Culture of sugar cane processing, mathematical modeling.

\footnotetext{
52 Estudante Ensino Médio, bolsista BIC / Jr. / UEMG. Link LATTES: http://buscatextual.cnpq.br/buscatextual/visualizacv.do?id=K8217930D7.

${ }^{53}$ Mestre em Ensino de Ciências e Doutoranda em Educação Matemática, docente da UEMG, Unidade Frutal, lotada no Depto. DCET. Contato: geisiane.santos@uemg.br.

54 Mestre em Psicologia e Saúde Mental, docente da UEMG, Unidade Frutal, lotada no Depto. DCH. Contato:itaceli@hotmail.com.
} 


\section{INTRODUÇÃO}

Delimitam-se neste trabalho, algumas mudanças ocorridas nas safras da região Sudeste, mais precisamente no Estado de Minas Gerais - Triângulo Mineiro, transformações as quais incidiram após o aumento da área plantada de cana-de-açúcar. Estas concentrações de cultivos se sobressaem mais precisamente no Município de Frutal - MG, que atualmente possui uma população estimada em 57.795 habitantes e uma área 2.426 .965 km² (IBGE, 2016).

Por anos seguidos, o Município de Frutal teve suas atividades econômicas focalizadas na produção agrícola e pecuária, com forte concentração na criação de gado leiteiro, na plantação de abacaxi, soja e laranja. Com o avanço das plantações de cana-de-açúcar, os produtores passaram a ter a oportunidade de mudar de atividade e ir para o setor sucroalcooleiro.

Em linhas gerais, a pesquisa teve por objetivo estabelecer conexões com os conceitos básicos de Estatística, introduzidos no currículo de Matemática e, especificamente, os voltados para os temas cotidianos, com vértice relacionado à evolução das lavouras temporárias, nos períodos entre 2004 a 2014, no Município de Frutal, empregando-se a Estatística e a ferramenta digital conhecida como software Excel.

Assim, ao tratarmos do assunto voltado para as lavouras temporárias, primeiramente se fez necessário analisar o comportamento das safras no Município de Frutal e, por conseguinte, observar a organização do site do Instituto Brasileiro de Geografia e Estatística - IBGE, para coletarmos os referidos dados. A partir disso, verificou-se que a atividade agrícola do Município está dividida em três grupos, sendo o primeiro, o grupo dos cereais, leguminosas e oleaginosas, o segundo, as lavouras permanentes e, o terceiro as lavouras temporárias.

De forma simplificada, consideram-se como lavouras permanentes aquelas que não necessitam, após a colheita, de um novo plantio e de lavouras 
temporárias, as quais coabitam com aquelas que necessitam de um novo plantio após cada colheita.

Por uma questão de delimitação do escopo do artigo, elegeu-se como objeto de estudo, as lavouras temporárias e, ainda, num recorte temporal que varia entre o período de 2004 a 2014.

Considera-se a base de dados disponíveis no site do IBGE, no grupo das lavouras temporárias, por conter as culturas que se obtém em safras, que foi o foco do presente trabalho.

Para fundamentar a pesquisa, pesquisadores e os alunos participantes impetraram um recorte de investigação (DINIZ, 2007), de acordo com a realidade, utilizando-se do estudo da matemática propostos pela Modelagem Matemática (BARBOSA, 2001).

\section{METODOLOGIA DA PESQUISA}

Para alcançar os objetivos propostos, foram estabelecidos os seguintes critérios: (1) trabalhar a interdisciplinaridade de Matemática com a área de Geografia, por meio da definição do tema; (2) levantamento bibliográfico sobre o tema; (3) visita ao IBGE - Instituto Brasileiro de Geografia e Estatística e à UEMG - Universidade do Estado de Minas Gerais, Unidade de Frutal; (4) abordagem dos princípios gerais da Estatística; (5) uso de tecnologias; (6) coleta, organização, descrição; e, (7) análise e interpretação dos dados coletados.

O trabalho interdisciplinar de Matemática com a área de Geografia ocorreu após a escolha do tema pelo bolsista e pela equipe integrante do projeto. Assim, a formação foi composta por um professor de Geografia, dois alunos bolsistas, um professor da UEMG e uma professora orientadora.

O levantamento bibliográfico foi realizado em pesquisas direcionadas com a temática proposta e que, após a leitura, definiram-se aquelas que seriam utilizadas na pesquisa. 
A partir da construção de um questionário, realizou-se uma visita ao IBGE, na Unidade Frutal e, posteriormente, novas consultas foram feitas na mesma Unidade Acadêmica.

O uso do laboratório de Geomática, na UEMG, Unidade Frutal, possibilitou a inserção do uso ampliado da tecnologia e, ainda, o contato com a Universidade e seus centros de pesquisa.

O laboratório de informática da escola de origem do bolsista foi o local de encontro das orientações e, ainda, o local de busca de informações estabeleceu-se por intermédio de pesquisa on-line.

A abordagem dos princípios gerais da Estatística, para o nível de escolarização do estudante, foi realizada em consonância com o que se propõe no Currículo Básico Comum ( $\mathrm{CBC}$ ), de Minas Gerais, no eixo temático IV, Tratamento de Dados, no que se refere ao desenvolvimento das habilidades:

Organizar e tabular um conjunto de dados; interpretar e utilizar dados apresentados em tabelas; utilizar um gráfico de colunas para representar um conjunto de dados; interpretar e utilizar dados gráficos num gráfico de colunas (SEEMG, 2005, p. 30).

O uso das tecnologias deu sustentação à pesquisa, à leitura de artigos e dissertações disponibilizadas na internet, e o uso do software Excel, concomitantemente.

A coleta dos dados foi feita no site do IBGE, a organização e tabulação permitiram a confecção de gráficos.

A análise dos dados e a conclusão final da pesquisa constituíram-se no momento de olhar para os questionamentos e estruturar os rumos para pesquisas posteriores. 


\section{RESULTADOS DA ANÁLISE DOS DADOS}

Com ênfase nas principais culturas temporárias produzidas no Município de Frutal, entende-se que o cultivo do abacaxi, no Brasil, teve um crescimento expressivo na década de 90 e no ano de 1998.

Desse modo os Estados de Minas Gerais, Belém do Pará, Paraíba e Bahia foram os maiores produtores, com $68 \%$ da produção nacional (EMBRAPA, 2000).

A pesquisa de Guimarães (2015) fornece a quantidade produzida de abacaxi a partir de 1999:

Figura 1 - Produção de Abacaxi

Tabela 4-Frutal (MG): área plantada e quantidade produzida de abacaxi (1990 à 2013)

\begin{tabular}{c|cc}
\hline Ano & $\begin{array}{c}\text { Área plantada } \\
\text { (ha) }\end{array}$ & $\begin{array}{c}\text { Quantidade } \\
\text { produzida (milhöes frutos) }\end{array}$ \\
\hline 1990 & 1.794 & 31.761 \\
1992 & 1.820 & 32.760 \\
1994 & 3.120 & 56.160 \\
1996 & 3.400 & 68.000 \\
1998 & 3.250 & 65.000 \\
2000 & 4.200 & 88.200 \\
2002 & 2.500 & 75.000 \\
2004 & 1.500 & 45.000 \\
2006 & 1.600 & 48.000 \\
2008 & 1.600 & 48.000 \\
2010 & 1.900 & 57.000 \\
2011 & 1.900 & 57.000 \\
2012 & 2.100 & 52.500 \\
2013 & 1.600 & 48.000 \\
\hline
\end{tabular}

Fonte: IBGE, Produção Agricola Municipal 1990 à 2013. Org.:. GUIMARÃES, A. R., 2014.

Fonte: GUIMARÃES, 2015, p. 87. 
De acordo com a tabela acima, observamos que a produção de abacaxi, na cidade de Frutal, apresentou um declínio significativo a partir de 2002 , devido à inserção de novas lavouras, como, por exemplo, a de cana-de-açúcar. No ano de 2000, a quantidade produzida foi de 88.200 milhões de frutos (GUIMARÃES, 2015).

Retrata-se, na figura abaixo, a produção no período analisado pela pesquisa:

\section{PRODUÇÃO DE ABACAXI FRUTAL - 2004-2014}

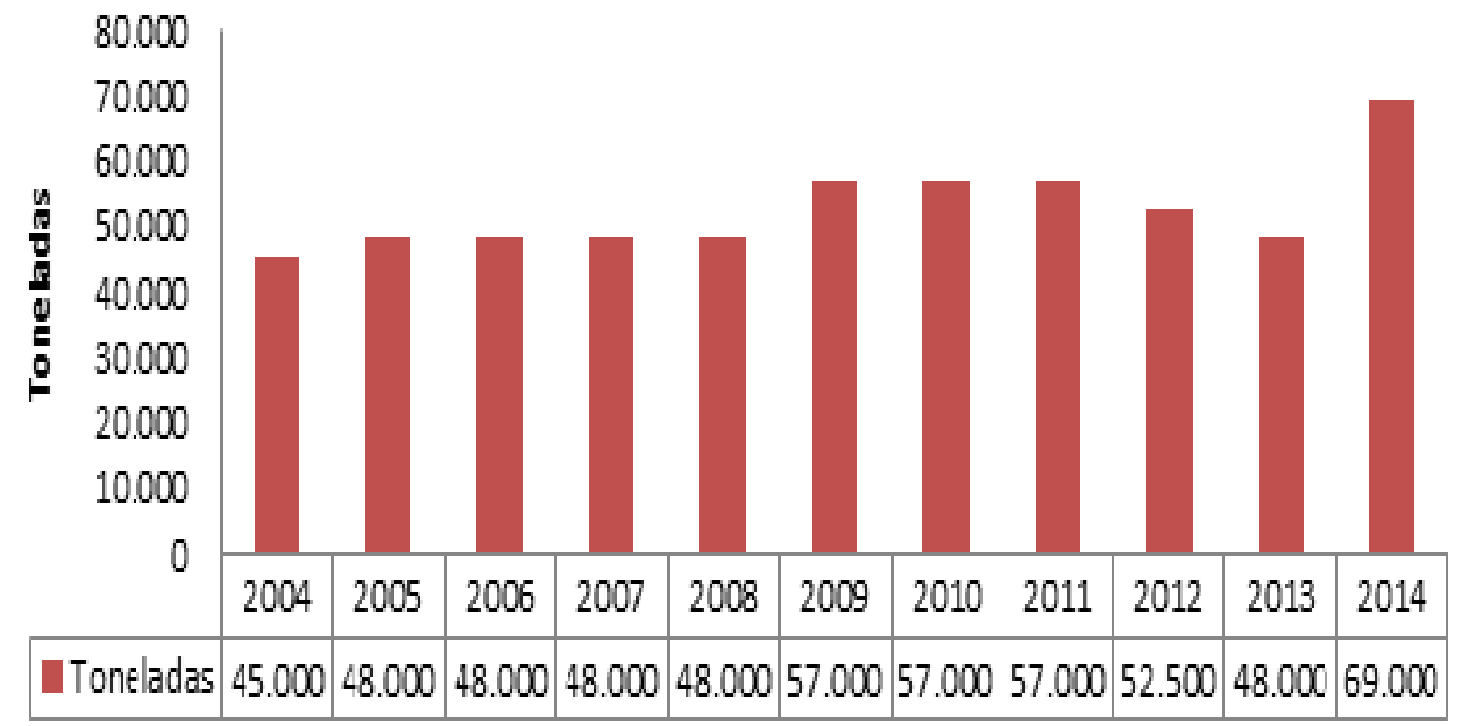

Fonte: IBGE, 2016.

Figura 2 - Expansão da Cultura de Abacaxi no Município.

A produção de abacaxi, no período considerado acima, de 2004 a 2014, apresentou uma tendência de alta. Apesar da produção, entre os anos de 2012 e 2013 sofrer uma queda, ainda foi maior que em relação ao ano de 2004.

Já, em 2014, houve uma recuperação expressiva neste setor, mas ainda não superando a produção de abacaxi em que foi demonstrada no ano de 2000. 
Outra cultura evidenciada no município foi a produção de amendoim:

\section{PRODUÇÃO DE AMENDOIN FRUTAL - 2004-2014}

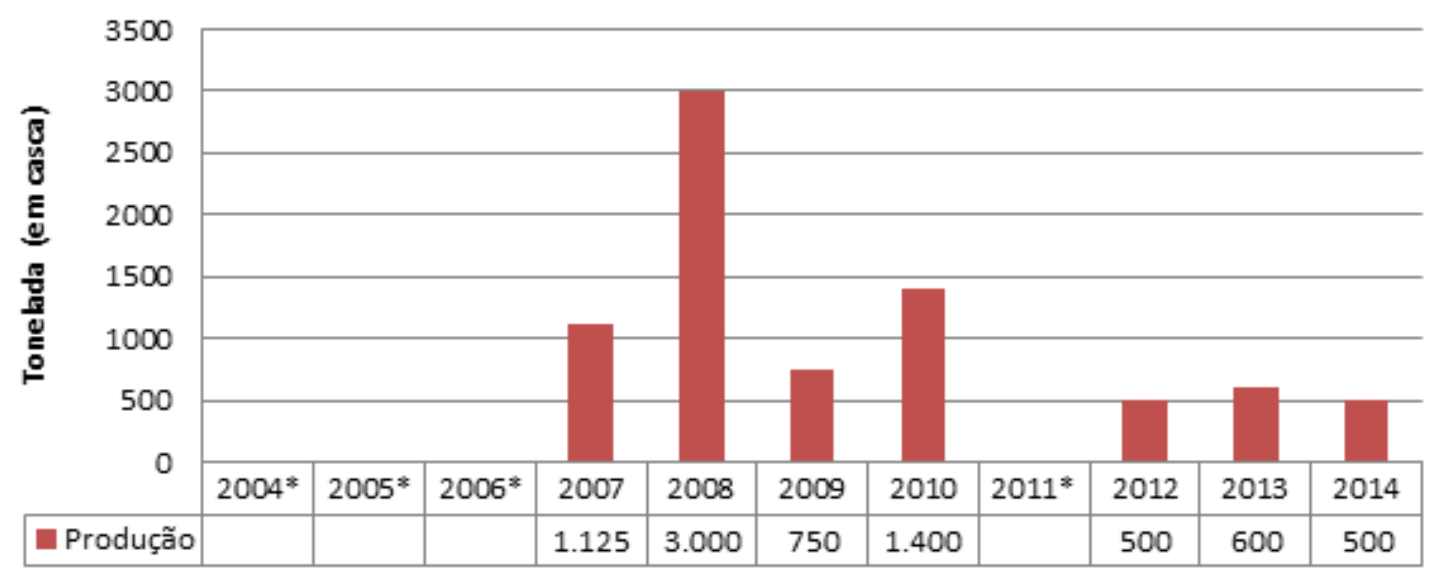

Figura 3 - Expansão da Cultura de Amendoim no Município* Fonte: IBGE, 2016.

O que se observa é que essa cultura de amendoim não teve ascensão no município.

Dando sequência ao estudo acerca das culturas, a evolução da produção de arroz verificada na figura abaixo:

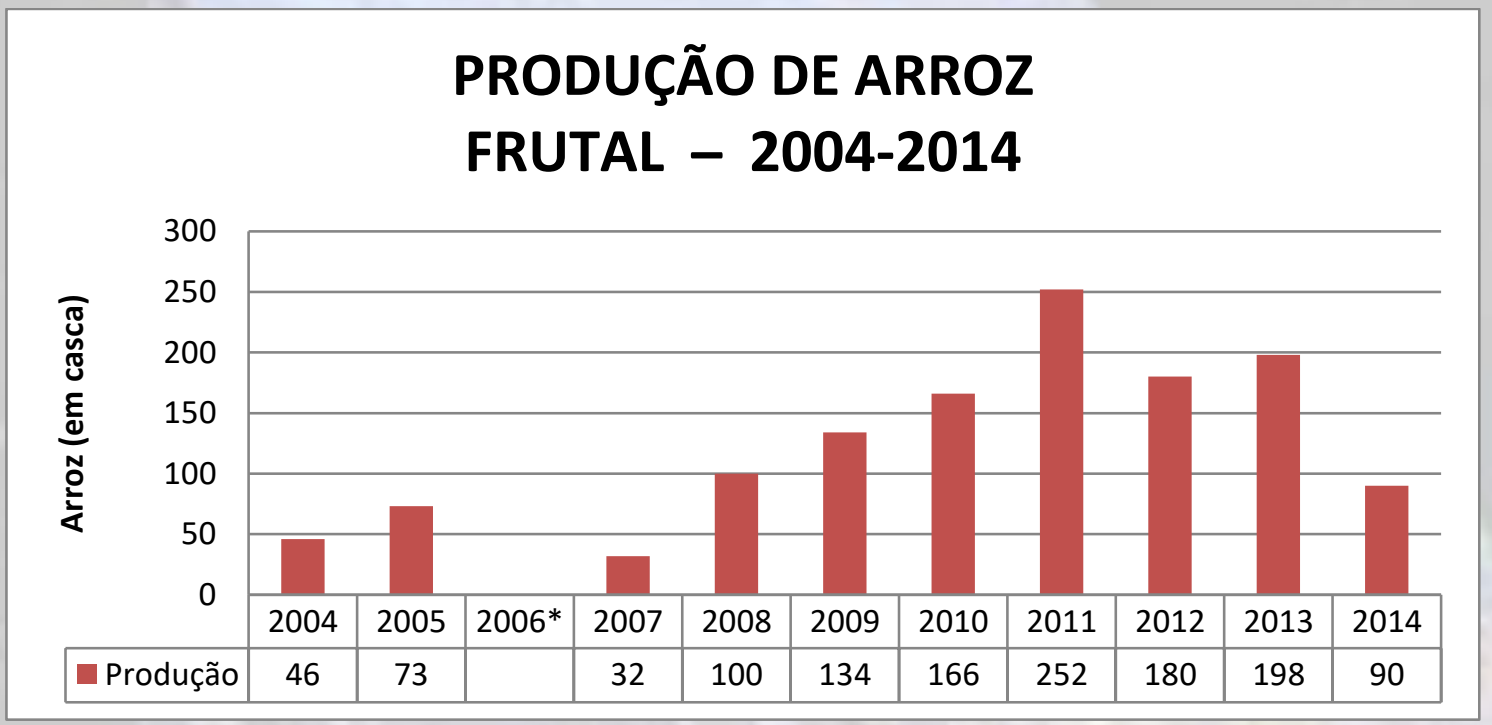

Figura 4 - Expansão da Cultura de Arroz no Município*.

Fonte: IBGE, 2016.

\footnotetext{
* Não obtemos os dados.
} 
Como observamos acima, a cultura de arroz também não teve um desenvolvimento contínuo, oscilando com índice alto em 2011, e com declínio em 2014.

Outra cultura temporária observada foi a cana-de-açúcar, conforme mostrou-se abaixo:

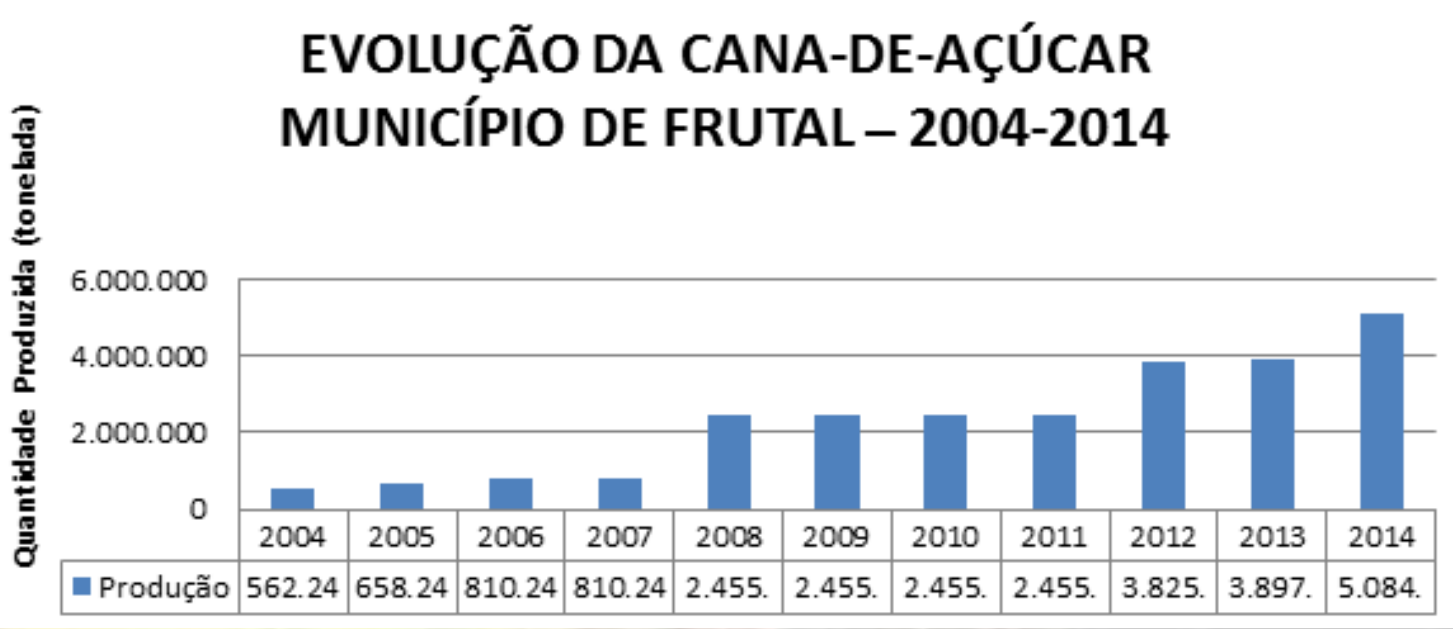

Como observamos, a cultura da cana-de-açúcar teve uma ascensão significativa, diferente das outras culturas analisadas.

Segue abaixo, mais dados sobre um cultivo que busca manter-se no mercado agrícola municipal:

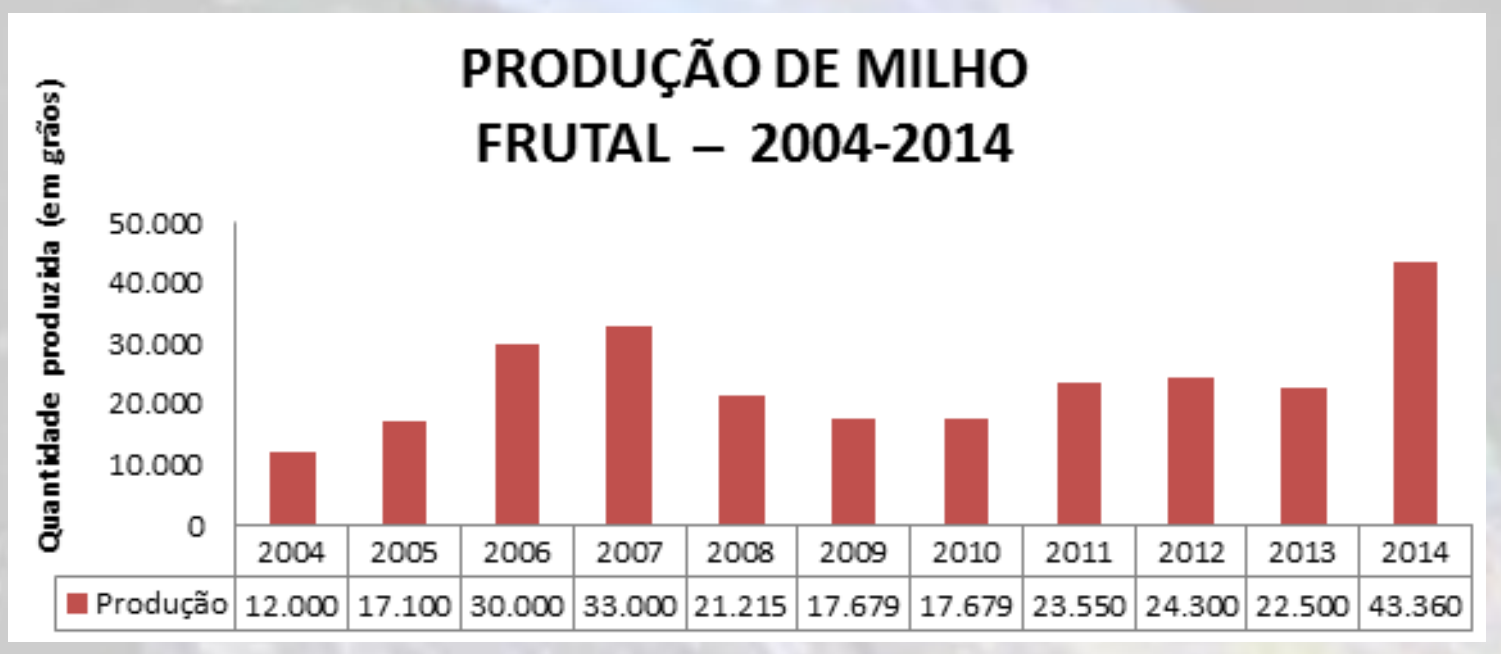

Figura - Expansão da Cultura de Milho no Município.

Fonte: IBGE, 2016. 
A cultura do milho começa a se elevar a partir de 2014, mas não se compara ao crescimento contínuo que a cana-de-açúcar obteve no mesmo período avaliado. Nas figuras 6 e 7, postas a seguir, notamos que houve uma diminuição na quantidade produzida:

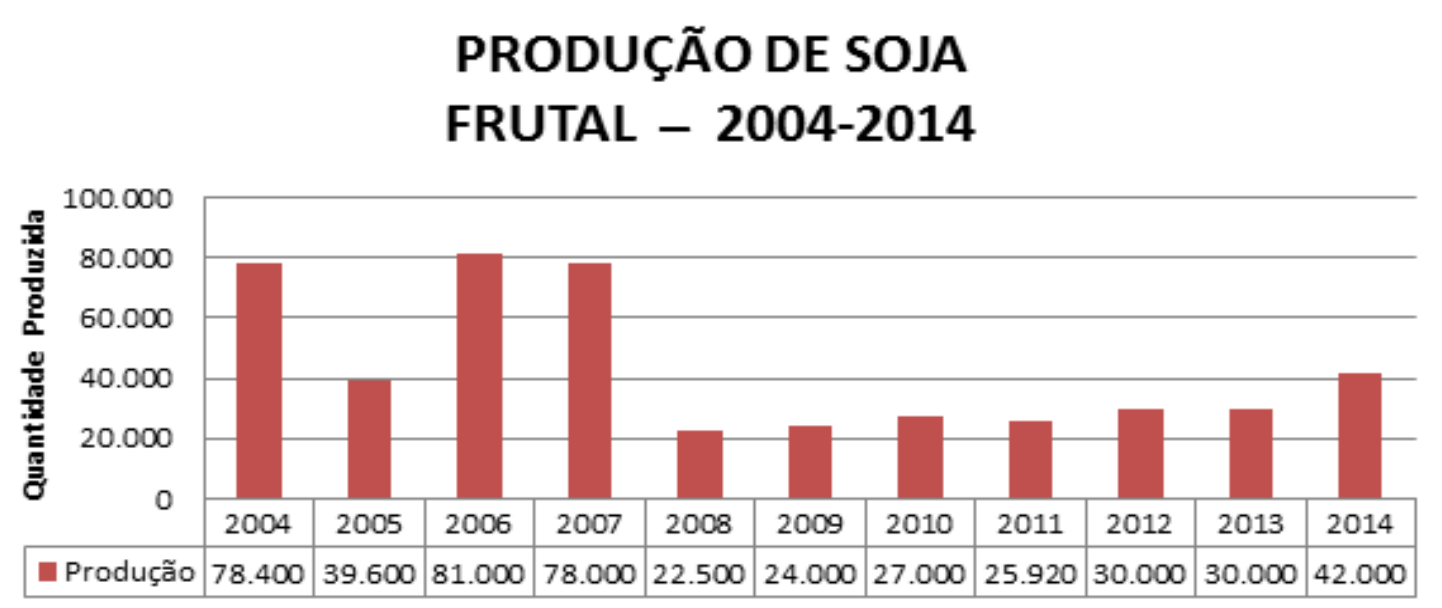

Figura 6 - Expansão da Cultura de Soja no Município.

Fonte: IBGE, 2016.

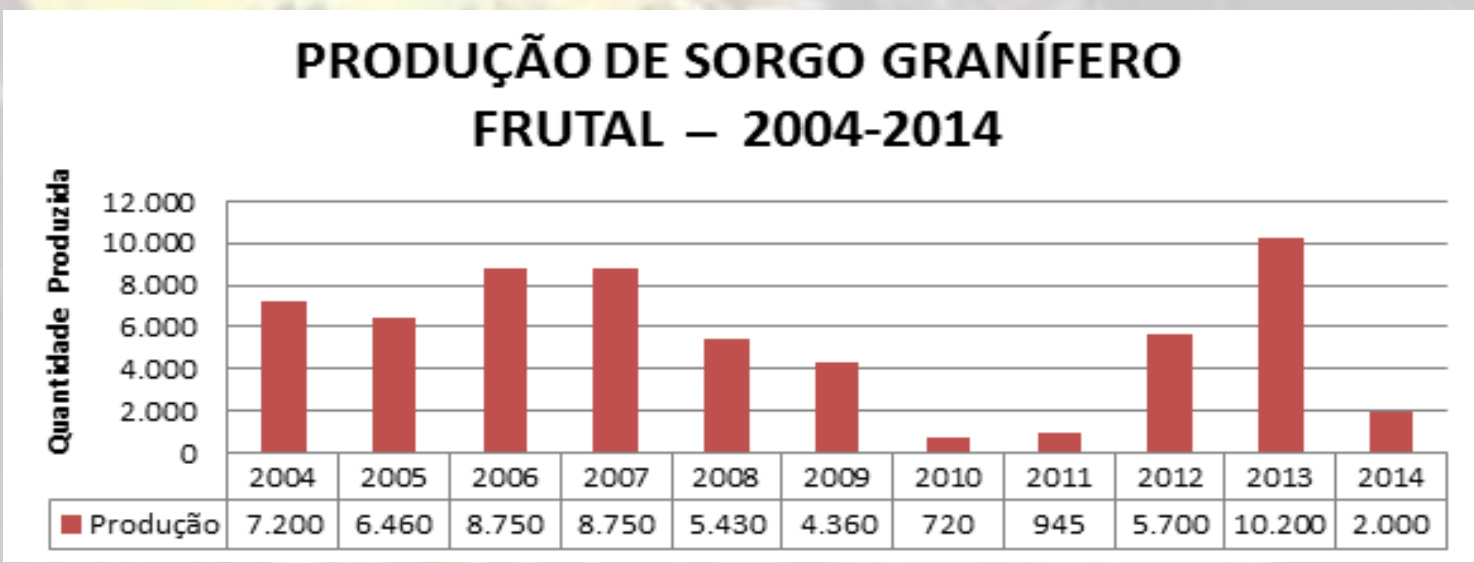

Figura 7 - Expansão da Cultura de Sorgo no Município.

Fonte: IBGE, 2016.

Assim, conseguimos verificar que, no período mencionado, enquanto a cana-de-açúcar teve um desenvolvimento significativo, as outras lavouras temporárias não obtiveram a mesma elevação.

Por último, ilustramos no gráfico abaixo a evolução de todas as lavouras temporárias analisadas no Município de Frutal, tendo como referência o ano de 2004: 


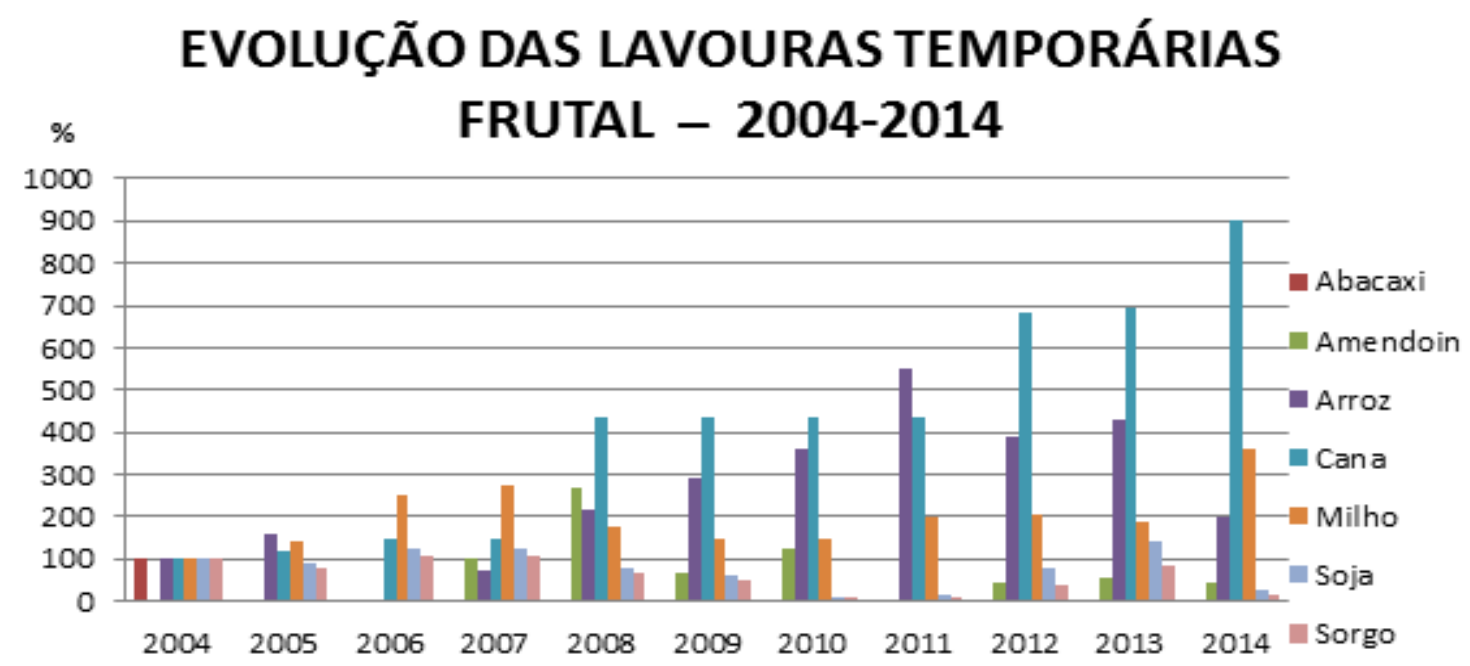

Figura 8 - Evolução das Lavouras, tendo como base o ano de 2004 Fonte: IBGE, 2016.

Assim, verificamos a expansão e a redução das culturas temporárias no Município de Frutal, as quais foram abordadas na presente pesquisa. Nota-se que houve uma redução na produção de milho e de arroz no período analisado, ao mesmo tempo em que evidenciamos o aumento da produção da cana-deaçúcar. Ou seja, os valores obtidos em 2004, resultaram posteriormente em um percentual de $100 \%$.

\section{CONCLUSÃO E DISCUSSÃO DOS RESULTADOS}

A expansão do setor sucroalcooleiro inibiu o crescimento das demais culturas temporárias praticadas no Município. Trata-se de uma reflexão futura acerca da diminuição da plantação de alimentos para a população, além de outros fatores, como o das mudanças climáticas, a da baixa fertilidade dos solos, o êxodo rural, dentre outros. Com isto*, evidencia-se uma redução da produção de alimentos e uma expansão na produção de cana-de-açúcar, no município de Frutal - MG.

* Não obtivemos os dados. 


\section{REFERÊNCIAS}

BARBOSA, J. C. Modelagem na educação matemática: contribuições para o debate teórico. In: Anais da REUNIÃO ANUAL DA ANPED, 24, 2001, Caxambu. Caxambu: ANPED, 2001. 1 CD - ROM.

A 'contextualização' e a modelagem na educação matemática do Ensino Médio. In: Anais do ENCONTRO NACIONAL DE EDUCAÇÃO MATEMÁTICA, 7., 2004. Recife: SBEM, 2004.

BASSANEZI, R. R. Modelagem Matemática - Um Método Científico de Pesquisa ou uma Estratégia de Ensino e Aprendizagem? In: BASSANEZI, R. R. Ensino - Aprendizagem com Modelagem Matemática: Uma Nova Estratégia. São Paulo: Contexto, 2002.

DINIZ, L. N. O papel das tecnologias da informação e comunicação nos projetos de modelagem matemática. Dissertação (Mestrado em Educação Matemática) - Instituto de Geociências e Ciências Exatas, Universidade Estadual Paulista, Rio Claro, 2007.

Empresa Brasileira de Pesquisa Agropecuária (EMBRAPA). Disponível em http://www.frutvasf.univasf.edu.br/images/abacaxi.pdf. Acesso em 20 de maio de 2015.

GUIMARÃES, A. R. A PRODUÇÃO DE ABACAXI: estratégias de reprodução da agricultura familiar no município de Monte Alegre de Minas (MG). Dissertação de mestrado. 2015.2 Disponível em: https://repositorio.bc.ufg.br/tede/bitstream/tede/4506/5/Disserta\%C3\%A7\%C3\%A30\%20\%20Alessandra\%20Rodrigues\%20Guimar\%C3\%A3es\%20-\%202015.pdf. Acesso em 15/05/2015.

Instituto Brasileiro de Geografia e Estatística (IBGE). Disponível em http://www.cidades.ibge.gov.br/xtras/perfil.php?lang=\&codmun=312710. Acesso em: 08 de abril de 2016.

A produção Agrícola Municipal. Volume 40. CD ROM. Disponível em http://biblioteca.ibge.gov.br/visualizacao/periodicos/66/pam 2013 v40 br.pdf. Acesso em 05 de maio de 2015.

PREVITALLI, F. S. FAGIANI, C. C. LUCENA, C. FRANÇA, R. L. A expansão da agroindústria na região do triângulo mineiro/Brasil e implicações sobre o trabalho. Sine loc / sine die.

SEEMG. SECRETARIA DE ESTADO DE EDUCAÇÃO DE MINAS GERAIS. CBC: Conteúdo Básico Comum - Matemática (2005). Educação Básica - Ensino Fundamental (5 $5^{\text {a }}$ a $\quad 8^{\text {a }}$ séries) Disponível em: http://crv.educacao.mg.gov.br/SISTEMA CRV/banco objetos crv/\%7B4DA513B4-34534B47-A322- 13CD37811A9C\%7D Matemática\%20final.pdf. Acesso em 30/10/2016.

SOUZA, A. G. A territorialização do Agronegócio Canavieiro em Frutal - MG. Dissertação (Mestrado). Universidade Federal de Uberlândia, Uberlândia, 2012.

TEODORO, M. A. OLIVEIRA, J.A. CASTANHO, R. B. Uma análise da produção agrícola da microrregião geográfica de Frutal (MG) a partir de mapas temáticos. In: Anais do Congresso Brasileiros de Geógrafos, 7, 2014. Vitória: CBG, 2014. 1 CD - ROM.

SOUZA, A. G. CLEPS JÚNIOR, J. O desenvolvimento do setor sucroalcooleiro no triângulo mineiro e seus efeitos sobre a produção de alimentos e trabalho rural. In: Anais do Encontro de Grupos de Pesquisa, 7, 2009. 